Salud e inmigración en Argentina.

Una historia compartida 


\section{Salud e inmigración en Argentina. Una historia compartida}

\section{Presentación}

A proponer como tema de análisis la interconexión entre inmigración y salud en una nación protagonista de la llegada (y partida) de miles y miles de personas, queríamos acentuar una de las problemáticas claves y poco explorada hasta el momento. Dado que la inmigración y la salud son fenómenos globales y a la vez, locales, la convocatoria a este diálogo incluyó a distintos especialistas, tanto argentinos como extranjeros, cuyos avances penetran en aspectos en diferentes niveles y contextos. La comparación, ejercicio usado y abusado por la profesión, es una herramienta importante para singularizar y abarcar a la vez el "caso" nacional en contraposición en países de matriz inmigratoria y a su vez, aplicarla en regiones cuya estructura dependió de población de ultramar. La historiografía de la salud y la enfermedad otorga sin duda una significativa base para la interpretación de índices demográficos de análisis -natalidad, mortalidad, morbilidad, fecundidad...- así como de su modificación en el tiempo.

Desde luego, una de las mayores transformaciones técnico-científicas del siglo XIX, con directa consecuencia sobre el alargamiento de la esperanza de vida de la población, fue la revolución de la microbiología. Tanto la investigación bacterológica como sus implicancias técnico-profesionales concretas, tuvieron un enorme impacto en la vida humana ${ }^{2}$ y abrieron el camino a la configuración de un campo de expertos y a su vinculación, más estrecha, con la formación de organismos públicos, así como a una mayor preocupación

\footnotetext{
1 Instituto de Estudios Socio-Históricos-Facultad de Ciencias Humanas-Universidad Nacional de La Pampa. Argentina. Correo electrónico: silviadiliscia@gmail.com

2 Sin ser exhaustivos, dos ejemplos como la medicalización del parto y la vacunación universal sirven para visualizar ese proceso.
} 
privada por la salud de los individuos y de las familias.

La inmigración, como la salud, no son fenómenos sencillos de abordar. En consecuencia, tampoco es posible hacerlo desde una mirada unívoca. Una y otra plantean una necesaria investigación del contexto global, pero a la vez es factible y deseable retornar al "caso" particular -localidades, áreas de circulación-, e incluso, a las historias y narraciones de inmigrantes.

En este dossier se abre un abanico de posibilidades: la enfermedad como una clave para el análisis social y clasista de los inmigrantes, como plantea el artículo de Fernanda Rebelo-Pinto y Gilberto Hochman sobre el cólera, peligrosa enfermedad epidémica. A través del examen de fuentes de diverso tipo, periodísticas y oficiales, se desgrana la experiencia traumática del viaje a través del mar y la llegada en los buques. También sobre la xenofobia que ejercen los agentes estatales, primeros y a veces únicos representantes frente a la población extranjera. Dado que la legislación brasileña considera solo a los pasajeros de segunda y tercera categoría como inmigrantes, el examen médico para detectar una enfermedad se diferencia de los de primera, quienes arriban con certificados de buena salud. Así, en "Cólera en el vapor Araguaya, 1910: la experiencia con la enfermedad en la travesía inmigratoria entre Europa, Brasil y Argentina", los autores analizan a través del caso de un vapor la particularidad de las definiciones científicas sobre la enfermedad, cuya descripción y terapéutica eran aún oscuras.

Los prejuicios sobre los italianos y otros extranjeros pobres hacinados en los puentes eran tales que los facultativos no dudaron en considerarlos enfermos de cólera y así, condenarlos al aislamiento, el contagio y la muerte. Y como el ingreso del cólera "asiático", enfermedad que se distribuyó en todo el mundo y con frecuencia mortal a principios del siglo XX, muchas otras dolencias plantearon debates acerca de la circulación de las personas, el tráfico de mercancías y el control sanitario en los puertos. Este fenómeno, por lo tanto, no es exclusivo de Brasil, sino que tuvo incidencia en otros puntos del Río de la Plata y significó una puesta en común entre éste y gobiernos de distinto signo político de Argentina y Uruguay. Conferencias y congresos internacionales para regular las normativas entre los Estados jalonan las primeras décadas del siglo $\mathrm{XX}$, antes de la existencia de la Sociedad de Naciones y el panamericanismo. La pretensión de mantener la salud dentro del país, a través de una escalada de medidas higiénicas para evitar las epidemias, resultó también un pretexto para regular las complejas relaciones sociales, cuando las élites positivistas proponían el "blanqueo" de la población a través del ingreso de europeos y su selección apuntando al peligro social de "agitadores" y "anarquistas" extranjeros.

También el poder es el eje del artículo de Emma Gioia, en relación a 
las políticas migratorias argentinas y el tracoma, patología contagiosa, crónica y producto de la pobreza. Esta enfermedad llegó al extremo sur de América a través de los ojos de los migrantes del este y centro de Europa, del Cercano Oriente y del norte de África. Fueron los "no deseados" pero también imprescindibles trabajadores a quienes se permitía ingresar al país previa inspección en el puerto de Buenos Aires. Como en Río de Janeiro, los médicos autorizaron el ingreso a los inmigrantes en sintonía para asegurar una masa laboral sana y obediente, en coincidencia con una reglamentación que insistía en definir las cualidades óptimas del inmigrante con las del trabajador manual. Pero el tracoma, como el cólera, fueron también parte de la agenda internacional de investigación médica, que requería precisiones no solo para expulsar sino para lograr un efectivo tratamiento terapéutico de miles y miles de brazos en áreas tan distantes como El Cairo, Nueva York, Santos, Marruecos, Bombay y Argelia. El análisis del caso argentino es útil entonces para asomarnos al examen de las complejas redes de interconexión científica, de sus expertos, de las definiciones nosológicas y a su "especialidad" continental en una patología que afectaba economías y sistemas políticos coloniales.

Los inmigrantes no se detuvieron, como es lógico, en el puerto; ni su papel lo definen y acotan los organismos estatales. Como es bien sabido, modificaron el perfil demográfico, la economía y la cultura de diferentes naciones americanas y dada su incidencia en la población argentina, este país sigue siendo uno de los más interesantes para el estudio de sus asociaciones y organizaciones. En el artículo "Entre tradiciones, regionalismos y socorros mutuos. El asociacionismo español en la zona del Golfo San Jorge (1910-1959)" de Edda Lía Crespo, se observan los afanes y esfuerzos de vascos y gallegos por proponer y defender un temprano y primitivo sistema de atención sanitaria y social. La Patagonia, reducto de los míticos indígenas tehuelches y de los cientos de miles de ovinos de las estancias inglesas, fue también el lugar elegido por muchos inmigrantes, motivados por el sueño de las enormes potencialidades y riquezas de esa América soñada. Los problemas de salud, unidos a la indefensión social de aquellos marginados del ámbito laboral y familiar (desocupados, menores y ancianos), fomentaron las asociaciones étnicas de ayuda mutua, en las cuales los españoles iban a buscar -no siempre a encontrar- el apoyo financiero y moral entre los de la misma tierra. A esos aspectos asociativos, se le añade en este artículo la influencia creciente de organismos locales de salud pública, incipientes a principio de la etapa estudiada pero con mayor fortaleza a mediados del siglo XX.

El binomio salud-inmigración resulta también interesante en su exploración hacia adentro. Más allá del retorno e ida-vuelta entre la implicancia del 
contagio y la sociedad higiénica que se moldea frente a sus rechazos, determinadas enfermedades aluden a otro vínculo, poco analizado y, sin embargo, de gran interés: la pertenencia a un grupo local, en el seno nacional. Acostumbrados a los discursos sobre inclusión o expulsión de pobladores extranjeros (seamos aún más precisos, de otros Estado-nación), los historiadores no hemos prestado similar atención a las pronunciadas y todavía salvajes exclusiones internas. Los hospitales, hasta la actualidad, ejercen ese papel: recursos técnicos y humanos limitados y amplitud de la demanda dan como resultado una competencia por obtener la legitimidad de la atención médica. Tal es el caso planteado en el artículo "Tuberculosis y migración hacia Córdoba durante las primeras décadas del siglo XX: discursos y concepciones en torno a la figura del migrante interno" presentado por María Laura Rodríguez, Lila Aizenberg y Adrián Carbonetti, donde frente a una de las enfermedades crónicas más emblemáticas por su potente carga de muerte y debilidad, se aceleran los factores de cohesión de los propios y, consecuentemente, de disrupción frente a los ajenos. Sin embargo, aquí no funciona las estrategias - de los médicos, de la prensa y los funcionarios- de señalar al "otro" (al extranjero) bajo el manto de la sospecha por el idioma, la religión, las costumbres, entre otros aspectos. En este caso, el tuberculoso extraño procede de una frontera provincial, habla en general el idioma español y es argentino, pero esa cercanía se deniega en virtud de su enfermedad y de las definiciones negativas del espacio. Así, el clima salutífero de Córdoba actúa como un factor aglutinante para los tísicos y a la vez, le imprime a la provincia toda ese mismo estigma.

Para los lectores especializados en historiografía de la salud y la enfermedad así como para los expertos en historia de la inmigración, estos relatos resultarán sin duda imprescindibles. Pero lo son además para los que están al margen de ambas problemáticas y desean encontrar líneas de reflexión sobre los nuevos aportes de la (amplia, indefinible en sus márgenes y a la vez apasionante), nueva historia social. 